\title{
Andalucía en imágenes: un viaje en el tiempo ${ }^{1}$
}

\author{
Ma Elena Baynat Monreal, IULMA-Universitat de Valencia, España
}

Resumen: Proponemos un viaje en el tiempo de tres siglos desde el siglo XIX hasta el XXI a través de la imagen exportada de Andalucía a los viajeros en diferentes soportes, según la época elegida: grabados en blanco y negro, dibujos en color y fotos en papel o digitalizadas. Para ello realizaremos un análisis comparativo entre las ilustraciones aparecidas en el relato de viajes francés sobre España de Alexandre Dumas (De Paris à Cadix) de 1847; las fotos y los dibujos del libro L'Espagne, los provinces du sud, de Séville à Cordoue escrito por Octave Aubry y publicado en 1929; y, para finalizar, las fotos promocionales aparecidas en la página web oficial de turismo de Andalucía (http://www.andalucia.org/) en 2012. El análisis de estas diferentes fuentes citadas, ejemplos de la primera mitad de cada siglo, nos servirá para estudiar algunas coincidencias y diferencias en la imagen exportada a los turistas extranjeros en las diferentes épocas así como los diversos criterios de selección de los atractivos turísticos o el mantenimiento o no de los estereotipos a lo largo de los siglos, entre otros aspectos.

Palabras clave: España, fotos, dibujos, grabados, turismo, viajes

\begin{abstract}
We propose a trip along time in three centuries -from the 19th to the 20th century-through the image of Andalusia exported to the travelers in different support media, according to the epoch chosen: etchings in white and black, colour drawings, and paper and digitalised photographs. With this aim in mind we will make a comparative analysis between the illustrations appearing in the French Travel story about Spain by Alexandre Dumas (De Paris à Cadix), from 1847, the pictures and drawings from the book L'Espagne, los provinces du sud, de Séville à Cordoue, written by Octave Aubry and published in 1929, and, finally, the promotional photographs appearing in Andalusia's official tourism webpage (http://www.andalucia.org/) in 2012. The analysis of the different sources aforementioned, examples from the first half of each century, will lead us to study some coincidences and differences in the image exported to foreign tourists in the different epochs as well as the different selection criteria of the tourist attractions or the prevalence or not of the stereotypes throughout centuries, among other aspects.
\end{abstract}

Keywords: Spain, Photography, Drawing, Etching, Tourism, Travel

\section{Introducción}

$\mathrm{E}$ estudio de la imagen o imagología aporta una nueva mirada hacia la literatura u otras ciencias humanas y pensamos que puede ayudarnos a comprender mejor las intenciones, miradas, mentalidades y pensamientos de los viajeros así como su visión del otro. Tal y como explicaba Ulagli en el primer congreso sobre imagología celebrado en Turquía en 2004:

L'image est une façon de percevoir le monde. On ne peut pas imaginer la représentation sans parler de la perception. Le sens d'une rose rouge, présentée à une femme, peut se former à condition que la femme connaisse la signification de la rose qui lui a été présentée par l'homme. Alors, ce qui est significatif dans l'image est la perception. L'image est le reflet de la perception et le commentaire de la réalité. Si on met l'image sous une loupe, on voit bien le rôle de la perception. (Ulagli, 2006: 21)

Es cierto que se trata de un enfoque de estudio complejo y multidisciplinar y que ha tenido diversos enfoques, orientaciones y precursores ${ }^{2}$ Podemos afirmar, sin embargo, tal y como explica

\footnotetext{
${ }^{1}$ Investigación realizada con la ayuda del Proyecto competitivo: Análisis léxico y discursivo de corpus paralelos y comparables (español, inglés y francés) de páginas electrónicas de promoción turística. FFI2011-24712, concedido por el Ministerio de Economía y Competitividad, en 2012-2014.

${ }^{2}$ Según Sánchez, por ejemplo, se consideran como precursores no científicos de la imagología a autores de la Época Clásica o cercanos a sus ideas cosmopolitas como por ejemplo los escritores alemanes Johann Gottlieb Herder, Johann Wolfgang von Goethe, Gotthold Ephraim Lessing o autores como Mme de Staël (Fischer 1981: 15).
}

Revista Internacional de Cultura Visual

Volumen 1, Número 1 <http://sobreculturavisual.com>, ISSN 2530-4666

(c) Global Knowledge Academics. M ${ }^{\text {a }}$ Elena Baynat Monreal. Todos los derechos reservados.

Permisos: soporte@gkacademics.com

Republicado de Revista Internacional de la Imagen 1(1), 2014 (pp.67-83) 
Sánchez $(2005)^{3}$, que existe una constante común en la ciencia de la imagología comparada que es la que nos interesa en este artículo: la necesidad de investigar el imagotipo en la literatura.

En consecuencia, para comprender las diferentes visiones del otro, los sentimientos y apreciaciones de los viajeros pensamos que conviene estudiar no solo sus comentarios y opiniones sino también la percepción de estos y para ello consideramos interesante analizar las imágenes que ilustran y acompañan lo escrito.

Nuestro análisis se centrará en tres ejemplos de textos turísticos ilustrados con imágenes que nos ayudarán a investigar y rastrear las similitudes y diferencias de percepción de Andalucía como destino turístico -imagen exportada e importada- de los tres últimos siglos.

En primer lugar hemos seleccionado De Paris à Cadix, un relato de viajes muy interesante desde el punto de vista literario puesto que pretende ser, por un lado, un relato romántico de España al estilo de su predecesor - Théophile Gautier ${ }^{4}$ - pero al que, por otro lado, el autor -indudable gran genio de la literatura popular y de aventuras francesa ${ }^{5}$ - ha añadido y fusionado componentes de otros géneros literarios, como la literatura de viajes o el teatro ${ }^{6}$. Aunque en los grabados que analizaremos no se percibe, al leer el relato se puede observar claramente que Dumas ofrece una visión de España y de los españoles menos romántica y más crítica e incluso a veces cínica que sus antecesores $^{7}$. Además la versión del viaje a España (De Paris à Cadix) que vamos a utilizar para nuestro análisis contiene unos grabados muy interesantes distribuidos a lo largo de todo el relato.

En segundo lugar, puesto que durante el siglo XX ya no está tan de moda el relato de viajes por España como en el siglo precedente (el XIX podría considerarse el siglo de oro del viaje, gracias, en parte, al romanticismo ${ }^{8}$ ) hemos decidido seleccionar un texto muy diferente, no por su calidad literaria sino por el valor de sus imágenes que es lo que nos interesa realmente en este estudio. Justificamos pues la selección de este volumen titulado L'Espagne, los provinces du sud, de Séville à Cordoue porque pensamos que los interesantes dibujos que aparecen en él muestran un buen ejemplo de la visión de Andalucía que se solía exportar a Francia durante el siglo XX. Dichos dibujos han sido realizados e ilustrados entre finales del XVIII y principios del XIX por el pintor francés orientalista Mariaus Hubert-Robert conocido por sus exposiciones ${ }^{9}$.

En tercer lugar hemos considerado interesante comparar la imagen de España exportada en el siglo XIX y XX a Francia con la que el turista actual puede encontrarse en el indiscutible punto de referencia actual previo a cualquier viaje: Internet. Tal y como han estudiado múltiples investigadores, actualmente el turismo y el viaje no pueden ser concebidos sin recurrir a la web, tanto desde el lado de la promoción como del consumo turístico. Tal y como afirma Sanmartín en el libro titulado Discurso turístico e Internet ${ }^{10}$ :

\footnotetext{
3 Cf. Referencias.

${ }^{4}$ El Voyage en Espagne de Gautier, publicado en 1840, es sin duda el relato de viaje a España más conocido y popular del siglo XIX en lengua francesa, uno de los relatos de viajes románticos más leídos e imitados que formó parte de la biblioteca del viajero de muchos otros turistas posteriores. El mismo Dumas imitó y plagió fragmentos de su Voyage en Espagne de manera consciente, alegando que puesto que Gautier lo había dicho antes mejor que él, prefería no repetir sus palabras.

${ }^{5}$ Citamos aquí el gran estudio biográfico del escritor realizado por Claude Shopp: Alexandre Dumas: le génie de la vie (cf. Referencias).

${ }^{6}$ Tenemos varios artículos escritos que demuestran esta vertiente literaria del resto de Dumas, citaremos:” De Paris à Cadix: una aventura muy teatral" (2006) (cf. Referencias).

${ }^{7}$ A diferencia de Gautier y otros viajeros románticos, Dumas no intenta integrase en la España del siglo XIX ni españolizarse, visita el España rodeado de un grupo de amigos y percibiendo al "otro" con una serie de prejuicios que no pretende descartar pero que sin embargo va perdiendo a medida que desciende hacia el sur, cuando la región andaluza y sus habitantes principalmente la mujeres, su punto débil— acaba seduciéndole y embrujándole.

${ }^{8}$ Numerosos investigadores entre los que se encuentra Soler (cf. Referencias) destacan el atractivo de esa exótica y romántica España que se convierte en el siglo XIX en modelo de país oriental y pintoresco para sus vecinos los franceses con la ventaja de la cercanía espacial.

${ }^{9}$ Citaremos su conocida exposición nu féminin années 1930 o su colección titulada City of Paris.

${ }^{10}$ Cf. Referencias.
} 
la red se ha convertido en una especie de agencia de viajes, en un sistema de promoción publicitaria de lugares y emplazamientos, en un punto de encuentro para conversar sobre experiencias del viaje y, por supuesto en un marco de interacción comunicativa inédito y apasionante para el estudioso del lenguaje. (Sanmartin, 2012: p. 10)

En efecto, consideramos que Internet ha sido definitivo en el sentido de que ha cambiado los modos de comunicarse y difundir la información en la actualidad y, en este sentido, pensamos que en un estudio sobre la imagen turística de Andalucía, además de analizar imágenes dibujadas es interesante añadir otras imágenes digitales para contrastarlas. Podríamos haber elegido algún blog de viajes, puesto que, como hemos analizado en otros estudios ${ }^{11}$, es el género de internet más parecido al relato de viajes tradicional, pero la mayoría de blogs que hemos seleccionado en la base de datos COME$\mathrm{TVAL}^{12}$, aunque han resultado interesantes por el texto que contenían, sin embargo, las fotografías incluidas ofrecían visiones muy parciales y demasiado particulares de los propios viajeros que se alejaban de nuestros objetivos: contenían principalmente imágenes personales de los viajeros en diferentes situaciones o lugares pero pocas del país visitado o de sus habitantes en general.

Puesto que lo que nos interesa es ver qué imagen de Andalucía se exporta en la actualidad a Francia para poder compararla con la de siglos anteriores, hemos pensado que lo mejor era elegir los espacios web que visitan sin duda la mayoría de viajeros franceses antes de su aventura por el sur de España; principalmente, la página web oficial de Andalucía, que sí ofrece imágenes comparables a las halladas en los textos de los siglos precedentes seleccionados para nuestro análisis.

\section{De Paris à Cadix}

Dumas, el gran viajero y aventurero, descubrió la España del siglo XIX, aprendió a amarla y a admirarla casi sin proponérselo ${ }^{13}$. Como hemos comentado, el tono principal de su relato de viajes es mucho más crítico, irónico y negativo que el de la mayoría de viajeros por España de su época pero, al adentrarse más en tierras españolas y, sobre todo, al atravesar Andalucía, el texto empieza a perder parte de este carácter peyorativo que tanto se le ha criticado y se empieza a vislumbrar el casi inevitable enamoramiento que esta exótica región ejerce en la mayoría sus visitantes y, por supuesto, también en el escritor.

Para nuestro análisis imagológico centrado en la fascinación producida por la región de Andalucía en los viajeros hemos elegido una edición de "De Paris à Cadix" del viaje incluida en la colección Impressions de voyage y editada por A. de Vasseur et Cie que aparece impresa con ilustraciones de Maillart, Daubigny, Gustave Doré, Worms, Foulquier, Gerlier, Giraud y Lix, entre otros. Sin embargo, algunas des estas ilustraciones no están firmadas. Esta edición, que no aparece fechada ${ }^{14}$, incluye varios relatos de viaje del autor: a Suiza, Italia, España, Túnez y otros destinos europeos.

La primera ilustración (sin título) que acompaña el comienzo del De Paris à Cadix de Dumas representa una de las escenas preferidas del escritor que describe con detalle en su relato:

\footnotetext{
${ }^{11}$ Citaremos nuestro capítulo de libro titulado "Turistas francófonos en España: análisis de testimonios y relatos de viajeros en blogs y foros de Internet" (2012). (Cf. Referencias)

12 En el proyecto COMETVAL citado anteriormente (ver cita $\mathrm{n}^{\mathrm{o}} 1$ ) en el que participamos como investigadores estamos analizando los diferentes géneros turísticos en Internet: páginas web institucionales y privadas (principalmente de hoteles), blogs de viajeros, foros, normativas, redes sociales, etc. Hemos creado una base de datos digital en la que hemos incluido textos de los diversos géneros, entre ellos más de 60 blogs de viajeros que al final hemos desestimado para este análisis por los criterios ya citados.

${ }^{13}$ El viaje a Dumas a España fue realmente circunstancial, venia de paso para ir a descubrir y promocionar el norte de África y, aprovechando las bodas reales, le financiaron el viaje a cambio de sus crónicas y relatos, con la excusa se pasó unos cuantos meses recorriendo y descubriendo España.

${ }^{14}$ En efecto, en este libro no hay escrita ninguna fecha de edición, sabemos que el relato fue editado por primera vez en 1847 y pero desconocemos la fecha real de publicación de esta edición.
} 


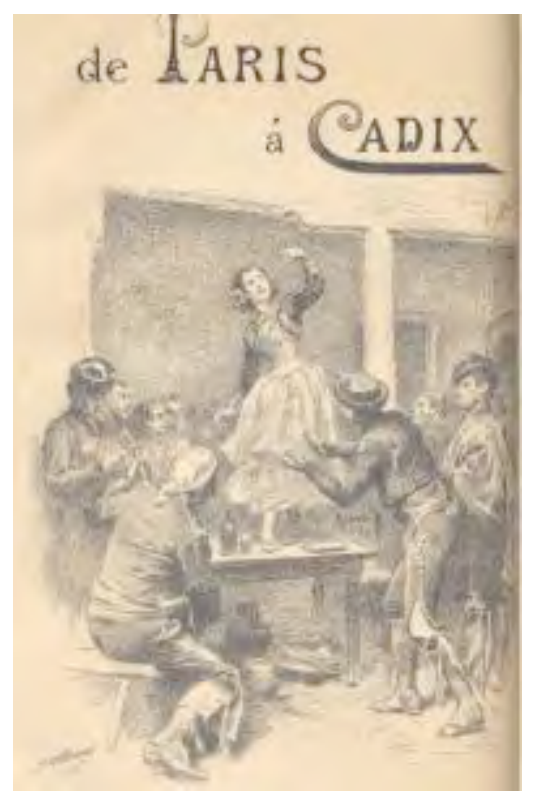

Fuente: Worms (18;?).

Como se puede observar, se trata de un grabado en blanco y negro que representa una escena folklorista en la que una mujer andaluza está bailando sobre una mesa de taberna rodeada por un grupo de hombres que cantan, la acompañan con sus instrumentos o aplauden. Esta imagen se refiere, sin duda, a una de las situaciones vividas por Dumas en Andalucía durante su viaje a España y que más le han marcado, puesto que, como todos sabemos, el escritor era un gran admirador de todas las mujeres. Como veremos, en estos pasajes en los que el autor describe escenas vividas en la región andaluza y, sobretodo, relacionadas con la música y el baile, es cuando deja de lado el sarcasmo y la burla que lo caracteriza hacia todo lo español -omnipresente a lo largo de todo el relatoy se deja al fin seducir: afloran sus sentimientos más íntimos admirando lo que ve sin tantos prejuicios o reticencias como en el resto del texto. Concluyendo, la primera imagen representativa de Dumas de Andalucía se centra en dos elementos privilegiados por el autor en su relato de viajes: la mujer y el baile.

A continuación, la imagen que aparece ilustrando el capítulo VI (primero del relato dedicado a Andalucía, concretamente a Jaén) tiene como título una frase que acompaña al grabado: «le bruit de notre accident s'était répandu dans la ville» (Dumas, 18??: 47). Esta afirmación es una buena muestra del orgullo de Dumas escritor quien en el momento de su viaje, ya era conocido mundialmente por sus novelas de aventuras y se siente importante porque la gente española habla de él; sin embargo, el dibujante aprovecha la situación para mostrar también un poco del pintoresquismo típico de cualquier relato de viajes que es lo que más interesa el lector de la época al que se dirige, mostrando con detalles la vestimenta típica y la vida cotidiana del pueblo: 
Figura 2: Le bruit de notre accident était répandu par la ville

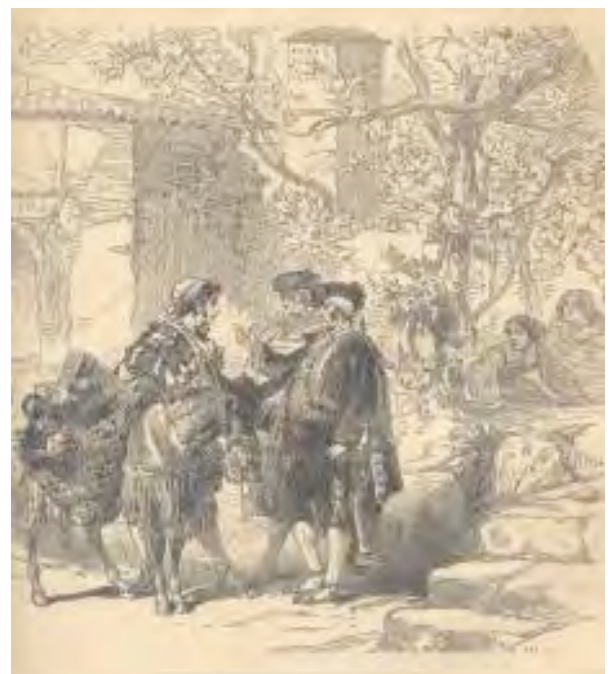

Fuente: Anónimo (18;?).

Es cierto que, no todos los lectores del siglo XIX podían permitirse un viaje a España real y muchos de ellos leían y admiraban las imágenes de estos relatos de viajes con gran avidez de evasión y curiosidad: estos textos aparecen publicados con frecuencia semanalmentepor capítulos en periódicos o revistas.

Debemos esperar tres capítulos más del relato -todos ellos dedicados a Granada- para encontrar al fin el tercer grabado de los episodios de su paso por Andalucía que se refiere también a una escena baile pero en este caso se trata de una pareja:

Figura 3: Les danseurs s'approchèrent peu à peu

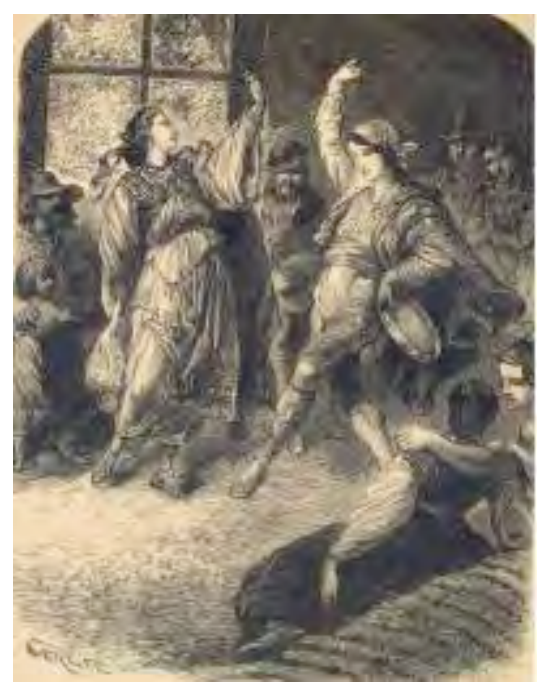

Fuente: Gerlier (18;?)

Se trata de una escena en la que hay movimiento, acción y teatralidad pero que, exceptuando el primer plano del grabado que representa a un chico cogiendo a una chica y mirándola a los ojos, no 
muestra la lujuria y obscenidad que Dumas muestra sentir al ver esta escena, lo que se puede observar claramente al leer la descripción de su relato en el texto que acompaña al grabado:

(...) animer les regards lascifs du frère et de la sœur. Mais ces regards devinrent de plus en plus provocateurs. Les danseurs se rapprochèrent peu à peu et se croisèrent( ...)prêts à s'abandonner au désir qui brûlait leurs yeux. (Dumas, 1847: 57)

Como se observa en el texto de la cita precedente, Dumas, traicionado por su subconsciente, quiere ver más allá de lo que la realidad le muestra y describe en su relato este baile entre hermanos como si se tratase de un acto sexual incestuoso que además le disgusta; así se observa si seleccionamos el vocabulario utilizado por el escritor en la descripción de esta escena que parece sacada de un relato erótico (en las citas hemos seguido el orden utilizado por él mismo):

balancement $(\ldots)$ faible mouvement de hanche(...)regards lascifs( ...) provocateurs( ...)se rapprochèrent peu à peu(...)en s'effleurant des lèvres(...)le combat des sens et de la pudeur(...)deux bouches à moitié confondues(...)s'abandonner au désir qui brûlait leurs yeux et les poussait l'un vers l'autre(...)cris obscènes $(\ldots)$ dernière excitation(...)le frère ôta son chapeau(...)sa sœur(...)renversait sa tête en arrière(...)donnait à ses reins la souplesse la plus provocante(...)le chapeau tomba(...)un sifflement aigu(...) l'expression du désir près d'être satisfait(..)il devint plus ardent, sa sœur plus folle(..)il la poursuivit(...)elle tombait dans la pose la plus épuisée(..)son frère s’arrêtât. (Dumas, 18 ¿?: 57-58)

Tras dos capítulos más del relato del viaje dedicados al traslado entre Córdoba y Granada ${ }^{15}$, en el XXI vemos al fin un grabado de paisaje en el que aparece una figura humana sola cabalgando que aparece como una sombra difuminada y en segundo plano. Lo que destaca el dibujante en el grabado que ilustra este capítulo es la pequeñez y soledad del viajero -Boulanger, uno de los acompañantes de Dumas- ante las inmensas montañas que lo rodean, la vegetación, las casas y los caminos andaluces que son las que ocupan la mayoría del grabado. Sin embargo el título del grabado da protagonismo a esa figura humana y no el paisaje:

Figura 4: Boulanger voyageait en chancellière

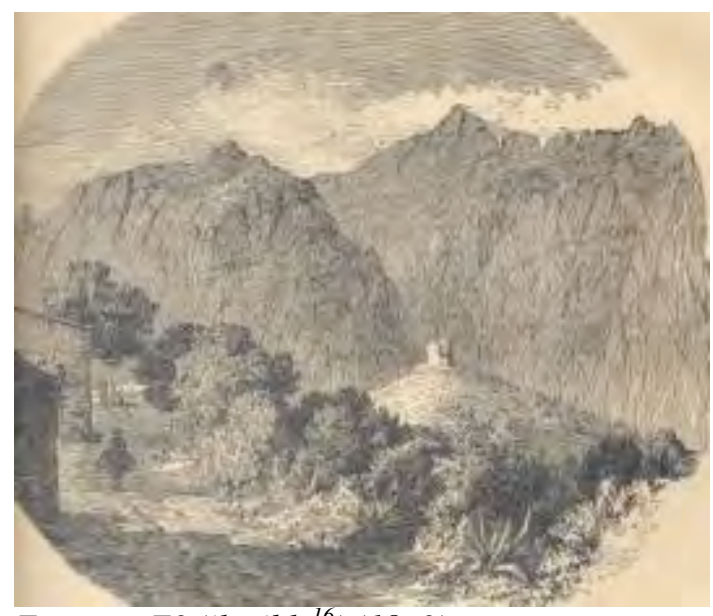

Fuente: ¿F? (ilegible $\left.{ }^{16}\right)\left(18_{i} ?\right)$.

Tras este grabado, encontramos varios capítulos más del texto dedicados a Córdoba y en el XXVII aparece el primer retrato con motivo andaluz: muletier espagnol. Debió de tratarse de uno de

\footnotetext{
15 En estos trayectos de ciudad en ciudad es en los que Dumas inserta su particular "novela cómica de aventuras" dentro del propio relato de viajes: una especie de representación teatral en la que "actúa" como protagonista con sus compañeros de viaje.

${ }^{16}$ Quizá el dibujante sea Foulquier puesto que parece leerse como primera letra de la firma una F.
} 
los guías acompañantes del viaje que dirigía a las mulas y el minucioso grabado sirve de excusa al dibujante para aportar un poco más de pintoresquismo al relato, mostrando los detalles del atuendo típico de algunos andaluces:

Figura 5: Muletier espagnol

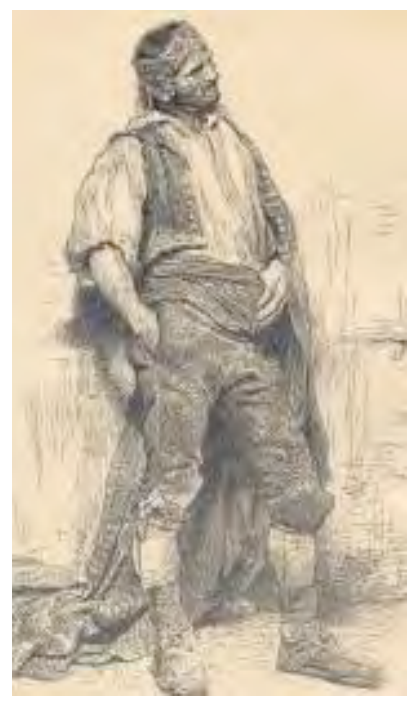

Fuente: Anónimo (18;?).

En el capítulo XX de De Paris à Cadix Dumas se dedica a describir lo que llama las princesas españolas (Dumas, 18 $i$ ?: 87) que describe en su relato como prostitutas; sin embargo el dibujo, el primero que aparece firmado por su autor -Giraud, uno de los compañeros de viaje de Dumas que es pintormuestra a una mujer vestida a la española, con mantilla, peineta y abanico, presentando un aspecto muy casto, una imagen que no tiene nada que ver con las descripciones de las indecorosas actividades que Dumas les otorga en el texto acompañante a lo que él considera, en tono sarcástico, las princesas:

Figura 6: Une princesse espagnole

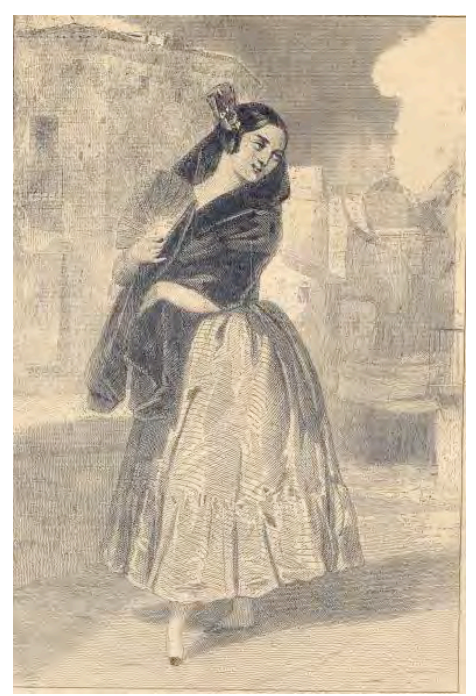

Fuente: Giraud (18;?). 
En el capítulo XXXIII del relato hallamos otro grabado de paisaje — similar al de la figura $\mathrm{n}^{\circ} 4$ citado anteriormente- titulado Nous quittions les dernières rampes de la sierra (Dumas, 18??: 95) directamente relacionado con la descripción del texto acompañante que describe un paisaje observado por el escritor en su camino.

Y no encontramos un grabado en color durante todo el relato de viaje por Andalucía hasta el capítulo XXVI, también anónimo (Dumas, 18 ¿?: 101): como se observa en la figura 7, este dibujo muestra a unas jovencitas españolas de mirada divertida y sugerente vestidas de un modo similar. En el fragmento del texto que acompaña al grabado Dumas muestra su entusiasmo y admiración frente a las bellas mujeres andaluzas que ha conocido y de las que se despide -según dice- "les larmes aux yeux" (Dumas, 18i?: 101). Esta imagen sirve de excusa al escritor para recordar en su relato a sus lectores que en España pudo comprobar como todo el mundo -incluidas estas jóvenes- había leído sus obras y lo reconocía, hecho que le ayuda a reforzar su conocida y ya de por sí subida autoestima. En el grabado destaca el color rojo de la flor del pelo, los labios, los abanicos y la camisa de una de las chicas que contrasta con el color moreno de sus cabellos y la sensualidad de sus ojos rasgados (imagen muy acorde, en este caso, con el texto que acompaña):

Figura 7: Il avait compté sans les beaux yeux des Elvires de la capitale

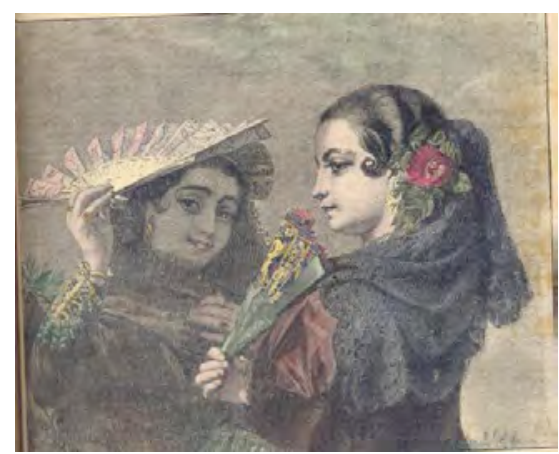

Fuente: Anónimo (18;?).

Y para cerrar el recorrido por Andalucía y del relato, en el capítulo XL (Dumas, 18¿?, p. 109), encontramos, al igual que al principio del texto, una nueva escena de baile, un grabado en blanco y negro, en este caso ubicado en Cádiz,que muestra a dos chicas idénticas bailando, las dos situadas en el centro de la escena, con el cuerpo en la misma posición: las bailarinas destacan ante un grupo de hombres y mujeres difuminados al fondo de la imagen que las observan. Este grabado se refiere a una de las emocionadas descripciones que hace Dumas en su relato (dos capítulos antes) de una escena de baile improvisada por dos mujeres andaluzas (Anita y Pietra), dos "bailaoras" que conoció durante su viaje y que emocionaron y encandilaron al enamoradizo Dumas:

Figura 8: Figurez-vous deux papillons qui courent et volent l'un après l'autre

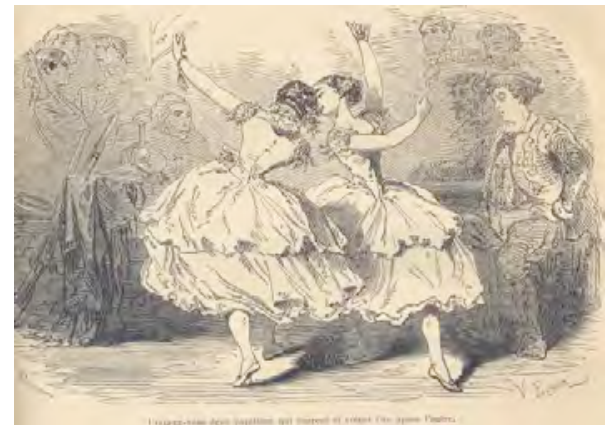

Fuente: Foulquier (18;?). 
Concluyendo, al observar el conjunto de ilustraciones que acompañan al relato de Dumas podemos hacernos una idea general de qué imagen de Andalucía y sus habitantes se prefería en el siglo XIX, qué aspectos focalizaban la mirada de algunos viajeros y dibujantes y cómo se presentaba a los lectores de la época para mostrarles "un pedacito" de la exótica y atractiva región sureña.

\section{L'Espagne, les provinces du sud, de Séville à Cordoue}

Como ya comentamos anteriormente, este libro de principios del siglo XX contiene fotos, dibujos y acuarelas de Marius Hubert-Robert acompañando a explicaciones dirigidas a los futuros turistas francófonos sobre lugares y aspectos de interés turístico destacables en el trayecto que va desde Sevilla hasta Córdoba. Para realizar nuestro análisis nos centraremos principalmente en las acuarelas del citado pintor observando, como hicimos con el relato de Dumas, el texto que las acompaña.

El primer dibujo que encontramos en el libro se refiere al barrio de los gitanos de Granada. En la imagen aparece una mujer anónima, sin rostro, andando por las calles de la ciudad; al contrario que en el relato de Dumas, que prefiere a las personas, el pintor, al elegir esta primera acuarela ha querido dar más importancia al ambiente y fisionomía de las calles como atractivo turístico que a sus gentes y a su folklore:

Figura 9: Grenade: le quartier des gitans

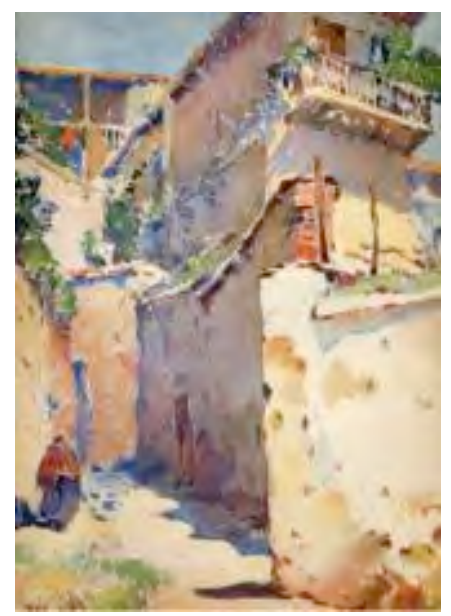

Fuente: Hubert-Robert (1929).

Las siguientes acuarelas que encontramos en el libro sirven para decorar el relato a modo de fotos ilustrativas que privilegian de un modo similar los paisajes, la vegetación, las flores y los monumentos. Observamos como en la mayoría de casos no hay relación directa con el texto al que acompañan: por ejemplo, otra acuarela el texto habla de las iglesias españolas y el fervor religioso de la semana santa sevillana incomprendido por los franceses: «le goût français en serait choqué, le goût espagnol s'y complaît» (Aubry, 1929: 40) y sin embargo el dibujo que lo acompaña muestra unas flores expuestas a la venta de la catedral de Sevilla:

Otro ejemplo de dibujo del texto que no mostraremos por su similitud al anterior tiene como motivo los jardines del Alcázar de Sevilla y, aunque está en consonancia con las fotos cercanas todas ellas sobre los mismos jardines-, ilustra, sin embargo, un fragmento del texto centrado en las corridas de toros. En este dibujo predominan, igual que en muchos otros del libro, los motivos vegetales y florales. 
Figura 10: Étalage du marchand de fleurs de la cathédrale

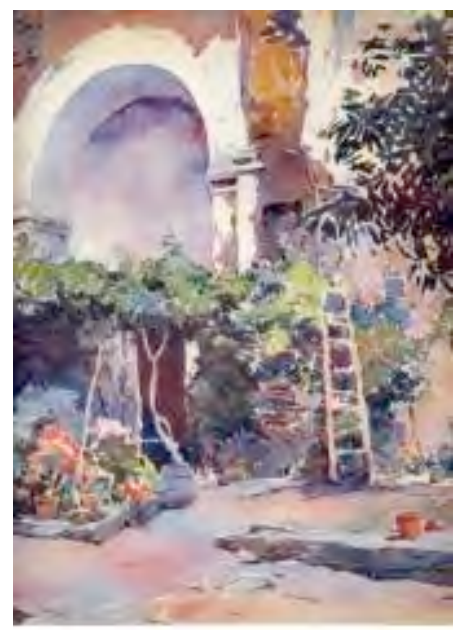

Fuente:: Huber t-Robert (1929).

De Granada hallamos tres acuarelas muy similares que se centran en un monumento andaluz excepcional — como no podía ser otro: la Alhambra- y en este caso sí que están relacionadas con las entusiasmadas descripciones del autor a la que acompañan (aunque no palabra a palabra como ocurría, en ocasiones, en el relato de Dumas): «quand on est tout en haut de 1'Alhambra, parmi les jardins, dans le murmure des sources, qu'on n'a plus devant soi que le déroulement de l'enceinte rouge, et là-haut, près de l'outre-mer si doux, la lueur de la Sierra, pareille à un cimier, l'âme oublie tout, soulevée de joie. L'esprit n'est plus captif de la terre. La sérénité le prend comme une belle vague(...)» (Aubry, 1929: 81-82). «les salles se succèdent aux salles, pareilles à des mitres d'or, d'écarlate et d'azur. Le miracle se renouvelle au-delà de chaque porte(..) » (Aubry, 1929: 90-91).

Figura 11: Grenade: patio de l'Alhambra cathédrale

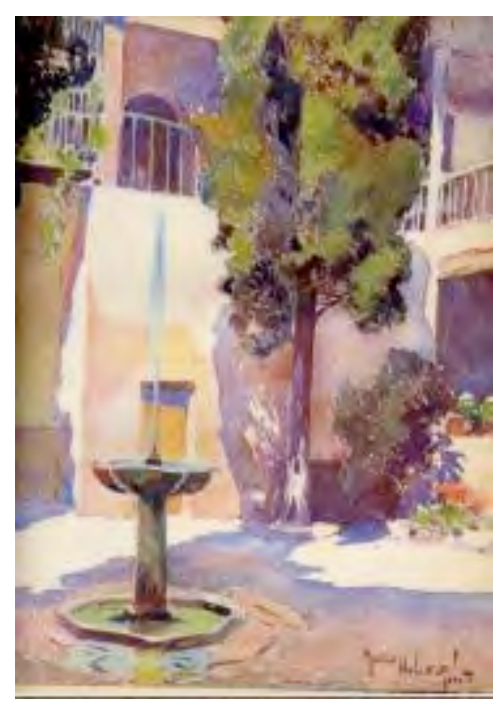

Fuente: Hubert-Robert (1929). 
La mayoría de las acuarelas que ilustran este relato van todas en la misma línea: paisajes, monumentos de ciudades andaluzas, jardines, patios interiores o paisajes exteriores con, en algunas ocasiones, personajes anónimos como elemento secundario que aportan pintoresquismo por sus vestiduras pero que quedan siempre relegados a un segundo plano, como por ejemplo una acuarela que representa el puente de Córdoba donde vemos a un hombre a caballo y una mujer desconocidos caminando:

Figura 12: Le Pont de Cordoue

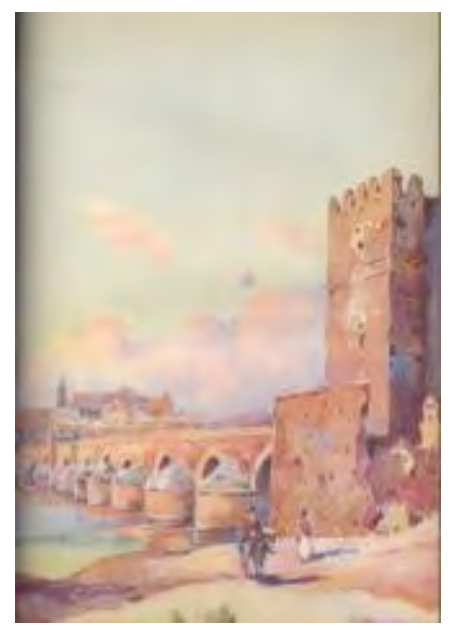

Fuente: Hubert-Robert (1929).

Sin embargo, en el libro encontramos también algunos dibujos y fotos (no acuarelas) de españoles-as en escenas típicas como desfiles de semana santa, corridas de toros, pescadores o el retrato de algún gitano (Aubry, 1929: 108) pero estos últimos son más objetivos y se pierde en ellos la individualidad, la teatralización y la novelización que mostraban los grabados del relato de Dumas. Al contrario, nos encontramos más bien frente a un reportaje costumbrista que presenta imágenes de una España monumental, de paisajes extraordinarios y habitantes anónimos acompañado, sin embargo, de comentarios exaltados y admirativos que buscan el lado más exótico, auténtico, pintoresco, oriental, remoto y romántico del país. Estos comentarios tan entusiastas y emotivos, más propios de un relato de viajes romántico como el de Gautier que, como el mismo autor reconoce, ha leído e influyen en su visión del país, contrastan, en definitiva, con las imágenes ilustrativas que los acompañan, que, como se puede observar en las imágenes ya mostradas, son mucho más objetivas y neutras. Mostremos algunas apreciaciones del autor sobre la España del siglo XX del texto analizado en las que se puede observar este entusiasmo por el país mediterráneo y los rasgos exóticos que encuentra en él y describe con emoción muy al estilo de los escritores románticos del siglo XIX:

L'Espagne n'a guère changé au cours du dernier siècle. Elle ressemble étonnament à l'Espagne que virent Chateaubriand et Alexandre Dumas. (Aubry, 1929: p. 20)

Les âges s'évaporent; le monde retourne en courant vers sa jeunesse. Grenade, comme elle fut, je la vois(...). (Aubry, 1929: p. 104)

A Baza, sur le chemin de Murcie(...) j'ai trouvé des gitanes, qui plus que celles de Grenade, gâtées par l'exploitations trop constante des étrangers, ont gardé leur mystère, leur saveur d'Asie. (Aubry, 1929: p. 124)

les maisons aussi ont gardé le caractère musulman. (Aubry, 1929: p. 156)

Como se observa en las citas anteriores, Aubry leyó también el relato de Dumas y otros viajeros del siglo XIX.

Resumiendo, las imágenes del siglo XX analizadas - la mayoría acuarelas en color-, aparte de las diferencias de formato con las del relato de Dumas -grabados, en su mayoría en blanco y negro- 
son supuestamente más objetivas en el sentido de que ofrecen una visión en teoría más imparcial (o menos romántica) de Andalucía, pretendiendo acercarse más al género reportaje o guía de viajes que al relato de viajes. Por otro lado, otra diferencia entre las imágenes del texto del s. XX analizadas y las del relato de viaje de Dumas es que los motivos que representan tienen menos relación con el texto al que acompañan. Estas acuarelas muestran, en definitiva, un buen ejemplo de la colorida Andalucía que el autor encontró cuando la visitó a principios del siglo principalmente una región rica en monumentos, vegetación y pintoresquismo. Sin embargo, como hemos podido comprobar en nuestro análisis, los comentarios que acompañan a las imágenes halladas en el libro de Aubry no son tan objetivos como los dibujos y recuerdan más a la imagen exótica y orientalista de la región que daban la mayoría de escritores románticos, como Gautier o Châteaubriand, sin embargo, se alejan del texto de Dumas. Esto último es debido, en parte, a la naturaleza de este último relato: en efecto, aunque perteneciendo por fechas al periodo del romanticismo y ofrecer también un cierto pintoresquismo heredado o voluntariamente "plagiado" de otros viajeros, este original de viajes relato se salta todas las premisas del género "clásico", instaurando una nueva y original versión de literatura de viajes novelada no exenta, sin embargo, de unas ilustrativas y exóticas imágenes.

\section{Página web oficial de turismo de Andalucía}

A continuación estudiaremos que imágenes y texto reclamo se utilizan en las principales páginas web oficiales de promoción turística en la actualidad (s. XXI) para promocionar la región andaluza; comprobaremos en este caso que hay elementos comunes o divergentes con las imágenes exportadas en los siglos anteriores y que ciertos estereotipos - provenientes en su mayoría aún de la época romántica, dos siglos antes- se han mantenido, mientras que otros han sido ya abandonados por obsoletos o excesivamente costumbristas.

La primera imagen que destaca en la página web oficial de Turismo de Andalucía ${ }^{18}$ es una foto del interior de la catedral de Córdoba lo que nos hace pensar que lo que más importa resaltar, en primer lugar, al igual que a principios de los siglos XIX y XX, es el exotismo representado por los monumentos andaluces de origen árabe. Sin embargo, esta imagen es la portada de un video promocional de Andalucía que añade numerosos elementos novedosos e intenta conjugar tradición y modernidad, al igual que otras campañas publicitarias de ciudades españolas de este siglo ${ }^{19}$. En efecto, en la página web analizada, se intenta vender la Andalucía tradicional, exótica y auténtica pero combinada con un toque de modernidad. El salto de siglo en este caso es gigantesco, no solo por la interactividad del soporte utilizado-por ejemplo, la inclusión de material audio-visual además de fotos- sino también porque, como hemos comentado, se combinan imágenes de los reclamos promocionales que destacaron los viajeros de los siglos anteriores -monumentos árabes, bailes tradicionales, corridas de toros, paisajes verdes y floreados, desfiles de semana santa...- con elementos innovadores del siglo XXI: tanto la vestimenta de las personas que aparecen en el video como otros lugares nuevos que se intercalan (balnearios, campos de golf, hoteles, playas, museos...). Las palabras clave que acompañan esta foto/video son una buena muestra representativa de esta bipolaridad y toque moderno: sol y playa, golf, deportes, cultura, naturaleza, salud y belleza.

Debajo de estos slogans, sin salir de la página principal, encontramos nuevas imágenes sobre eventos a los que se aconseja acudir a los turistas: estas imágenes son a su vez enlaces desde los que se puede acceder a otras páginas web explicativas del evento y con videos de youtube. Debemos destacar aquí la importancia del hecho de que la publicidad del s. XXI realizada a través de la web es rompedora e inno-

\footnotetext{
${ }^{17}$ En realidad la literatura de viajes se trata de un género tan amplio e interdisciplinar que es difícil limitarlo y definirlo, pudiendo englobar textos muy diversos y transversales; si que hay características similares entre los relatos (remitimos a los estudios de Carrizo Rueda, cf. Bibliografía) pero son textos que — como el de Dumas — pueden traspasar todas las fronteras entre géneros.

18 http://www.andalucia.org/ (fecha consulta 19/04/12)

${ }^{19}$ Tenemos un estudio publicado sobre la imagen exportada e importada de la ciudad de Valencia en la que también hemos observado este juego constante entre tradición y modernidad como elemento esencial del atractivo turístico de la ciudad mediterránea. Se trata de: El turista francés en Valencia: un viaje en el tiempo (del siglo XIX al XXI) (2011). (cf. Referencias)
} 
vadora en relación con la publicidad turística de siglos anteriores no solo por su gran difusión y accesibilidad por todo tipo de público sino también por su interactividad (la gran cantidad de información complementaria variada de todo tipo que se puede añadir a una simple página promocional).

Si analizamos las últimas imágenes citadas diremos que, en primer lugar, sirven para recomendar al viajero la visita de la feria de Sevilla; para ello se muestra una foto de mujeres subidas a caballos pero no vestidas de sevillanas sino con traje andaluz masculino (signo de modernidad y contraste con respecto a las campañas publicitarias de los siglos anteriores):

Figura 13: Página web oficial de turismo de Andalucía

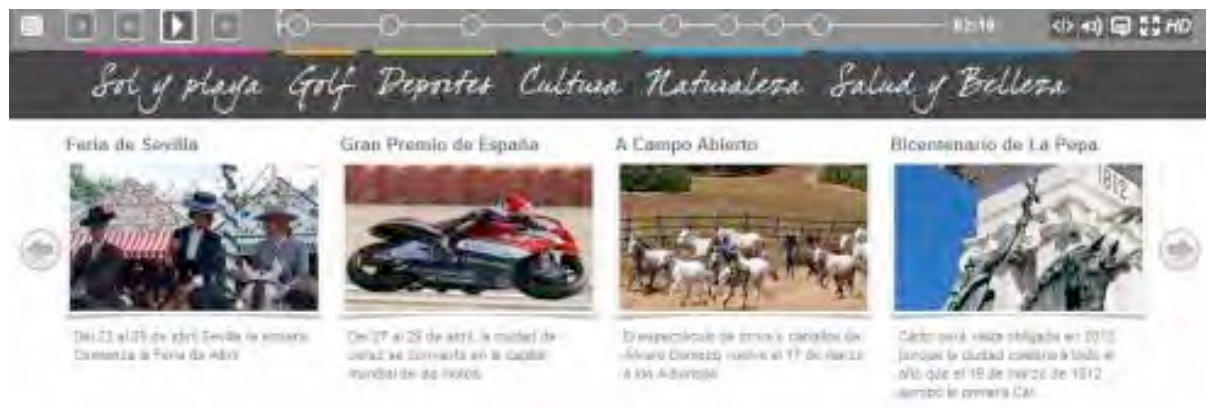

Fuente: http://www.andalucia.org

Como se observa en la imagen, junto a la feria de Sevilla se promociona el gran premio de motociclismo de España y un espectáculo de toros y caballos junto al bicentenario de la $\mathrm{Pepa}^{20}$ : una marcada fusión entre tradición y modernidad. A continuación, en la misma página, se hace publicidad también sobre acontecimientos culturales de interés turístico durante el mes de abril, como un festival de cine, un congreso o la feria de abril de Sevilla, y se ofrece enlaces a otras páginas web que informan con más detalle de esta oferta, siguiendo en la línea de combinar lo nuevo con lo antiguo.

El segundo ejemplo interesante de analizar es la página web Turismo Andalucía, otra página promocional que ofrece igualmente un aspecto moderno e interactivo, con enlaces internos a otras páginas web y, principalmente, a redes sociales como Twiter o Facebook:

Figura 13: Página web Turismo Andalucía

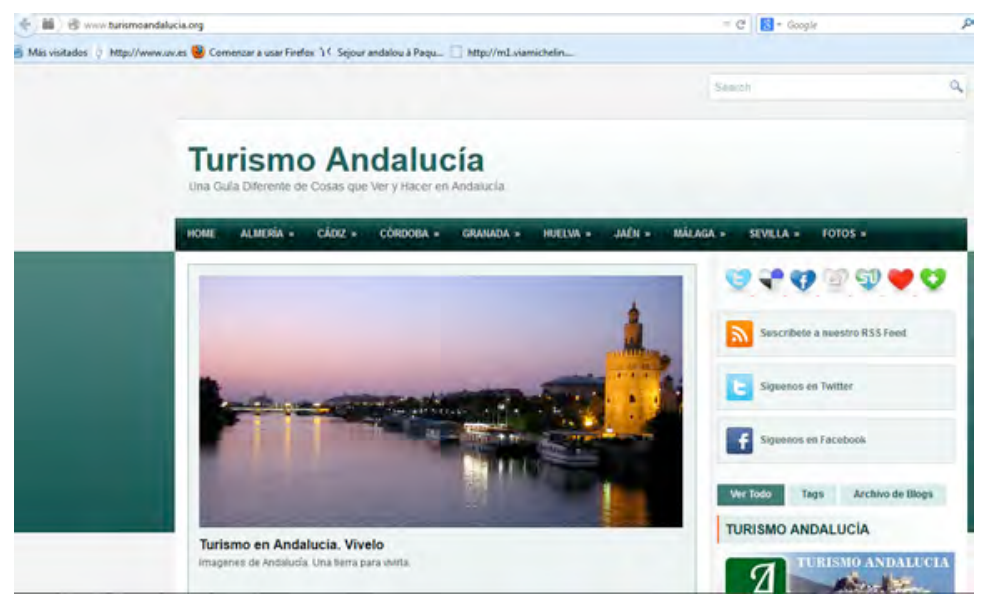

Fuente: http://www.turismoandalucia.org

${ }^{20}$ La primera constitución española de Cádiz. 
En la última página web citada, mostrada en la figura 13, aparecen diferentes fotografías de monumentos de la región que van sucediéndose una detrás de otra (en este caso hemos elegido mostrar la fotografía de la torre del oro de Sevilla) y el texto que las acompaña privilegia la imagen asociándola a sensaciones placenteras: «Turismo en Andalucía. Disfrútalo. Imágenes de Andalucía. Una tierra para disfrutarla» (http://www.turismoandalucia.org).

Citaremos en tercer lugar la página spain.info: en el apartado dedicado a Andalucía aparece una foto de la Giralda de Sevilla acompañada del siguiente texto que resume la imagen que se pretende exportar de la región en la actualidad:

Es tierra de cultura, historia, fiesta, naturaleza y muy buena comida. Visitarás desde impresionantes monumentos a un entorno natural lleno de contrastes, vivirás celebraciones populares únicas y degustarás productos muy sabrosos(...) Además, podrás disfrutar de fiestas como la Semana Santa, el Carnaval de Cádiz, el Rocío en Huelva o la Feria de Abril de Sevilla. (http://www.spain.info/es/quequieres/ciudades-pueblos/comunidades-autonomas/andalucia.html)

Terminaremos nuestro recorrido citando un video de youtube (vacaciones-españa.es) de 2011 en el que se muestra un resumen en imágenes de lo que ofrece Andalucía al turista en la actualidad: principalmente su clima, su cultura, sus paisajes, así como sus modernas y cómodas instalaciones, muestra de su modernidad, y una arraigada tradición folklórica representadas por los dos grandes tópicos, que como podemos observar, siguen eligiéndose como reclamo pintoresco de turistas (los toros y el flamenco):

Figura 15: Imágenes del video promocional de Andalucía de la página web vacaciones-españa.es

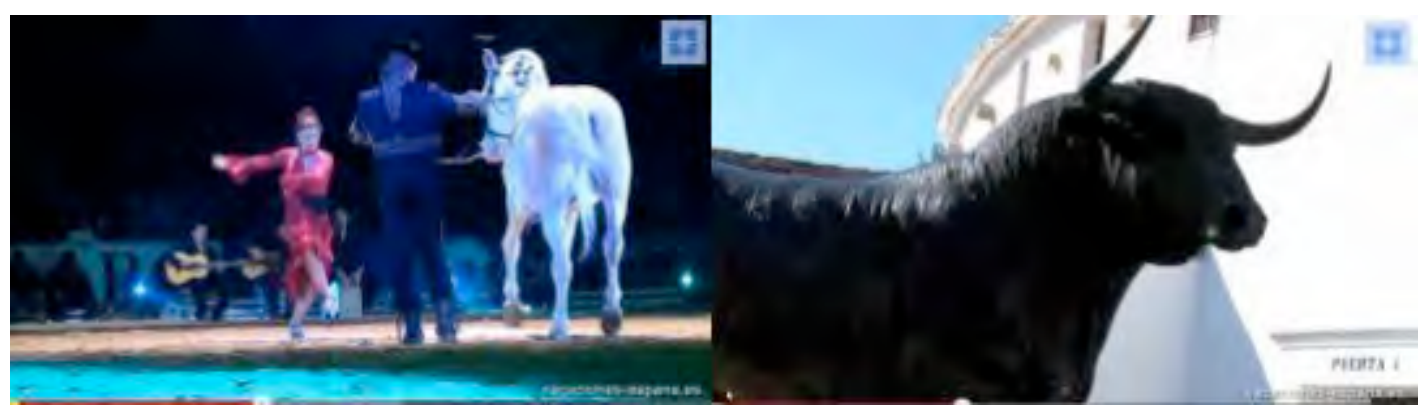

Fuente: http://www.youtube.com/watch?v=SJ7aLDGf_o8

\section{Conclusiones}

Tras realizar un análisis de algunos ejemplos ilustrativos sobre la imagen buscada y exportada de Andalucía en tres momentos puntuales de tres siglos distintos y en diferentes soportes, observamos que, según nuestro reducido corpus (somos conscientes de su mero carácter ejemplificativo), durante los siglos XIX y XX las miradas se dirigen, en general, hacia la Andalucía romántica y exótica, resaltando principalmente los siguientes centros de interés turístico: la mujer andaluza, los trajes regionales, la música y el baile, los verdes paisajes, el fervor religioso de la semana santa, la riqueza histórica y cultural de los monumentos orientales y la pureza racial de los gitanos. Sin embargo, al analizar la página web oficial de turismo de Andalucía actual (siglo XXI) hemos podido observar que la selección de imágenes ofrecidas como reclamo para los turistas combinan y alternan tradición y modernidad así como exotismo y vanguardismo: es decir que retoman la imagen de la Andalucía clásica exportada durante los siglos XIX y XX, con las mujeres y los caballos como principales protagonistas, pero dejan más de lado la música y el baile tan admirados en siglos anteriores. A principios del siglo XXI se sigue vendiendo la Andalucía de los grandes paisajes naturales, de los magníficos monumentos y de la riqueza cultural e histórica, bañada por el intenso sol: elementos inmutables tas el paso de los siglos. Sin embargo, se promociona también una región nueva y mo- 
dernizada en la que ocurren importantes acontecimientos culturales y deportivos y que ofrece unas instalaciones hoteleras modernas confortables donde se puede disfrutar, entre otros, de una oferta de turismo de salud y belleza, destacando también los bellos paisajes y, sobretodo, las magníficas playas donde disfrutar de baños de sol y de mar así como las verdes montañas que ofrecen nuevas y diferentes alternativas turísticas. El visitante actual puede disfrutar tanto de un turismo de sol y playa o de relax como de un turismo más activo y rural centrado en la aventura y el deporte (como protagonista o espectador).

Podemos decir, resumiendo, que la imagen clásica y romántica de la Andalucía de la pandereta, los gitanos y el peligro a lo desconocido, proveniente en gran parte del romanticismo y exportada en gran medida a través de relatos y guías de viaje durante los siglos XIX y XX, ha ido difuminándose y evolucionando durante el aun recientemente inaugurado siglo XXI. En efecto, en los ejemplos analizados, se siguen promocionando y exportando algunos aspectos de la Andalucía tradicional que aún atraen a los turistas pero, a su vez, se ha hecho un gran esfuerzo por luchar contra los estereotipos, tratando de ofrecer una imagen más modernizada y actualizada de la región que apueste por nuevas modalidades de turismo y que englobe un mayor campo de acción, es decir, que se dirija a un mayor abanico de clientela tanto extranjera como española, primando la diversión y el ocio. Debemos añadir que, tal como hemos comentado anteriormente, esta imagen se ha ido renovando y ha ido evolucionado no solo en su mensaje sino sobre todo en su formato y modo difusión: desde los grabados dibujados durante el viaje por los acompañantes de Dumas que ilustraban algunas versiones del libro hasta las recientes fotos y videos de las campañas publicitarias online publicadas en páginas web caracterizadas por su gran interacción y rápida accesibilidad desde cualquier lugar del mundo el salto es innegable.

Concluyendo, la imagen ha sido y sigue siendo el principal medio de atracción, difusión y propaganda turística: hemos pasado del grabado y el dibujo, a la fotografía y, finalmente, al video, pero la imagen -en papel o en pantalla - acompaña siempre al texto y, como hemos visto, es el principal foco de atracción de las miradas de los viajeros, pintores, fotógrafos y publicistas de los tres siglos analizados. Con este modesto análisis de algunas imágenes representativas de las épocas elegidas; esperamos haber ofrecido idea general de los aspectos que interesaban e interesan, tanto a los turistas que han visitado Andalucía como a aquellos que simplemente han querido o quieren conocerla a través de los testimonios, explicaciones y principalmente imágenes que otros les han ofrecido a través de diferentes formatos, estilos o soportes. Los siglos pasan pero la imagen perdura y deja huella. 


\section{REFERENCIAS}

AA.VV. (2006). Les modalités de la perception dans les représentations de l'altérité (Symposium International d'Imagologie). Mugla, Turquía: Éditeur Serhat Ulagli.

Aubry, O. (1929). L'Espagne: les provinces du sud, de Séville à Cordoue; acuarelas de Marius Hubert-Robert. Grenoble, Francia: Éditions B. Arthaud.

Baynat Monreal, M.E. (2006). De Paris à Cadix: una aventura muy teatral. En A. Dumas y Victor Hugo, Viaje de los textos y textos del viaje. Lleida: Ediciones de la Universitat de Lleida/Pagès Editors.

- (2011). El turista francés en Valencia: un viaje en el tiempo (del siglo XIX al XXI). Tiempo: texto e imagen. Temps: texte et image. Madrid, España: Editorial de la Universidad Complutense de Madrid.

- (2014). Turistas francófonos en España: análisis de testimonios y relatos de viajeros en blogs y foros de internet. En J. Sanmartín, Discurso turístico e Internet. Madrid, España: Editorial Iberoamericana Verbuet.

Cañizo Rueda, S. (1929). Poética del relato de viajes. Kassel: Reinchenberg.

Dumas, A. (¿18?). De Paris à Cadix. En Impressions de voyage. Paris, Francia: A. Le Vasseur et cie, éditeurs.

Gautier, Th. (1981). Voyage en Espagne. Paris, France: Gallimard.

Sánchez Romero, M. (2005). La investigación textual imagológica contemporánea y su aplicación en el análisis de obras literarias. Revista de Filología Alemana, 13. Extraído de: http://revistas.ucm.es/index.php/RFAL/article/view/RFAL0505110009A (última visita 25/07/2014)

Sanmartín, J. (2012). Discurso turístico e Internet. Madrid, España: Editorial Iberoamericana Verbuert. Shopp, C. (1985). Alexandre Dumas:le génie de la vie. Paris, Francia: Éditions Fayard.

Soler, P. E. (2006). El trabuco romántico. Viajeros franceses y bandoleros españoles en la Andalucía del siglo XIX. En M. Bruña, M.G. Caballos, I. Illanes, C. Ramírez y A. Raventós, La Cultura del Otro: Español en Francia, Francés en España (pp. 687-699). Sevilla, España: Publicaciones de la Universidad de Sevilla.

\section{Páginas web:}

COMETVAL. Corpus Multilingüe de Turismo de la Universitat de València: http://www.uv.es/ cometval/wikibase/cas/index.wiki (última visita: 24/10/14).

Página web oficial de Turismo de Andalucía: http://www.andalucia.org (última visita: 21/10/14) spain-holiday.com (2013). Andalucía (video promocional de la región). Extraído de: http://www. youtube.com/results?search_query=andaluc\%C3\%ADa+turismo\&sm=3 (última visita: 19/19/2014).

Spain Info: http://www.spain.info/es/que-quieres/ciudades-pueblos/comunidades-autonomas/ andalucia.html (última visita: 21/10/14)

Turismo Andalucía: http://www.turismoandalucia.org/ (última visita: 19/09/2014).

\section{SOBRE LA AUTORA}

$M^{a}$ Elena Baynat Monreal: Profesora contratada Doctor en la Universidad de Valencia. Doctora en Filología Románica por la Universidad de Valencia. Ha investigado y publicado sobre literatura del siglo XXI, literatura de viajes, la imagen de España en Francia, Metodologías docentes y Nuevas Tecnologías Aplicadas a la enseñanza de idiomas, Análisis de Corpus y Lexicología, y Francés para Fines Específicos (turismo y negocios internacionales). Actualmente pertenece al IULMA-Valencia (Instituto Interuniversitario de Lenguas Modernas Aplicadas). Algunas publicaciones: El poder de la 
palabra y la mirada en Carmen de Mérimée, L'image de la femme espagnole au XIXe siècle d'après Gautier et Mérimée: entre la réalité et le stéréotype, Los españoles/as del siglo XIX vistos por los viajeros franceses, TICS y créditos ECTS: una combinación ineludible en la Enseñanza-Aprendizaje de Lenguas, Vocabulari forestal: català-castellà-anglès-francès, Les «fallas » de Valencia : exportation et réception de l'image. 